\title{
THE ACTION OF RADIUM ON A VARIETY OF CUTANEOUS CONDITIONS
}

\author{
DOUGLASS W. MONTGOMERY, M.D. \\ AND \\ GEORGE D. CULVER, M.D. \\ SAN FRANCISCO
}

The use of radium in cancer, whether for amelioration of the symptoms or cure of the disease, is so beneficent that it has overshadowed its use in a great number of other affections. In the conditions discussed it has afforded us valuable service.

\section{PERSISTENT FISSURES OF THE NARES AND LIPS}

As the result of catarrh, cracks may form in the nares, especially frequently in the anterior angle. These are often associated with folliculitis of the vibrissae. The usual infective agent is a streptococcus, and it often gives rise to localized attacks of erysipelas, and after a time, to permanent redness of the nose. In fact, it is one of the principal causes of red nose. The best routine treatment is the use of boric acid fomentations, and the employment of a 12 per cent. calomel ointment, under which almost all cases will clear up. Some cases, however, are refractory.

A man, 37 years of age, had been under the care of a competent physician for this condition in the left nostril for one year before coming to us. The refractoriness in this case may have been due to inflammatory induration and to streptococci lying latent deep in this induration, as they are now known to do. We were confronted by an unusually stubborn case, and in addition to the boric acid fomentations and the calomel ointment, we employed radium.

On July 21 , two $25 \mathrm{mg}$. tubes, screened with a silver tube of $0.35 \mathrm{~mm}$. wall thickness and a rubber cot, were placed in the left nostril for fifteen minutes. By August 22 the condition was much improved, but there was still a little sensitiveness at the tip of the anterior angle. An $11 \mathrm{mg}$. radium plaque, shielded with a rubber cot, was placed over this region for five minutes. By September 15, the man had completely recovered, and we have heard of no relapse.

In this case it might be objected that radium with $0.35 \mathrm{~mm}$. silver screening for fifteen minutes would have no effect-that the screening was too heavy and the time too short. This tube, however, was itself highly radioactive as the radium was constantly kept in it.

Another instance of fissuring occurred in a soft, pulpy man of 49 , weighing 205 pounds, who had been troubled with the nasal condition for the previous three months. He was also afficted with cracking and irritation of the 
perineum and anus. After a preliminary treatment which proved ineffectual, radium was used in both situations. The relief was prompt; the anal discomfort disappeared within twenty-four hours.

\section{LUPUS ERYTHEMATOSUS}

To us one of the chief inducements for using radium was its favorable effect on that stubborn affection, lupus erythematosus. Its effect is greater than could be expected, for the eruption of lupus erythematosus is only a symptom and the real origin of this symptom lies in some hitherto not demonstrated internal affection.

We have found that the best results are obtained with very slight screening, and after an application of long duration. We employ a standard sized plaque which contains $11 \mathrm{mg}$. instead of $10 \mathrm{mg}$. of radium element, with a screen of two thicknesses of writing paper, for thirty minutes. Distance must always be considered an especially excellent screen, and distance is often secured by interposing cellulose, such as paper or felt. In lupus erythematosis, however, too great a distance is not desirable. A patient, an intelligent young man, deeply interested in his trouble and in the effect of radium on it, noted that the areas treated with the plaque in quite close contact with the affected surface, only screened with two thicknesses of writing paper, produced better results than when a thicker screen was interposed. A lead shield placed about the patch also interfered with obtaining the best results. Apparently close contact and wide inclusion of the margins, so as to radiate well beyond the visible border, is desirable.

DYSTROPHY OF THE NAILS IN SEBORRHEIC ECZEMA AND PSORIASIS

Sometimes in the disease above mentioned, the deformities of the nails are the most distressing lesions, as in the case of a dentist who thought he would have to change his occupation because his nails were so ugly and so difficult to clean.

On - Sept. 27, 1919, a woman consulted us concerning dystrophy of the nails. The trouble had begun one year before as a redness and crusting in the nail fold. The fourth and fifth fingernails of the right hand and the fourth finger of the left hand were affected. Besides this, she had seborrheic eczema of the nasolabial folds, patches of psoriasis on the right elbow tip and on the right leg just above the external maleolus.

Any one acquainted with the obduracy of these cases of seborrheic paronychia before the introduction of the roentgen-ray or radium will appreciate the results we have obtained through these mediums. In addition to general treatment, we employed lightly screened radium plaques over the nails for short periods of time. After a fairly strong reaction, the nails grew out normally. 


\section{LICHEN HYPERTROPHICUS}

The eruption of lichen planus is usually so widespread that roentgen-rays are much more easily utilized than radium, but recently we had a case of "white spot" disease with two hypertrophic lichen papules on the back of the neck. These papules were each $11 \mathrm{~mm}$. long and $6 \mathrm{~mm}$. broad. They were raised, oval, with a pale, rather milky colored border, and a rough center studded with follicular openings filled with small, horfy comedos. There were pale, milky bands rumning across the top of the papules between the follicular openings. Radium, lightly screened, acted well on these papules, and caused their disappearance. We doubt whether roentgen rays would have acted as well.

\section{VENEREAL WARTS}

A man, 21 years of age, while under treatment for syphilis, developed papillomas in the anterior part of the urethra. A $25 \mathrm{mg}$. tube of radium, enclosed in its silver capsule, $0.35 \mathrm{~mm}$. wall thickness, and covered with one thickness of writing paper and one thickness of zinc oxid adhesive plaster, was inserted and kept in place for forty-five minutes. This was done April 8, 1919, and by April 24 the papillomas were disappearing rapidly. In a short time they cleared up entirely, leaving no trace.

\section{PATCHES OF INDURATED ECZEMA}

There are patches of indurated eczema in .which the-induration and the pruritus are the main clinical features. These may be limited in extent, and as refractory to treatment as they are limited. The following case is a good example of this annoying affection.

A woman, 64 years of age, suffering from aortic regurgitation with marked pulsation in the neck, an enlarged liver, and sluggishness of the bowels, consuited us on account of a lump on the inner surface of the right natis. It was red, raised, rounded, sharply bounded, but was evidently eczematous and not neoplastic in its nature. It was not a keloid. We were able to reassure the patient in regard to tumor formation, but the prognosis as regards the cure of these cases is anything but good. As these patches are very itchy, the outlook is not cheerful. We were, however, able to control entirely the pruritus with salicylic acid plaster mull ( 5 per cent. strength). The thickening remained, however, and two or three days after discontinuing the use of plaster the pruritus would return. By April 27, 1917, the affection had improved, but there was still a small edematous, red patch left, which we knew would rapidly assume its original dimensions and irritability on removal of the salicylic acid plaster. We were frankly discouraged as far as the hope of achieving a permanent cure was concerned.

We were preparing the patient for a life-long use of this remedy when we fortunately employed radium. On April 27, 1917, after eighteen months of other treatment, a radium plaque containing $11 \mathrm{mg}$. of radium element was placed on the patch, shielded with one thickness of writing paper and one of rubber tissue, and retained ten minutes. This completely relieved the itch- 
ing, and there was no trace of the induration on June 12, 1917. To make sure, however, we again used this same plaque for ten minutes, screened with $0.50 \mathrm{mg}$. of aluminum. There has been no return of the condition since that time.

\section{COMMENT}

These few cases give some idea of the wide application of this remedial agent in diseases of the cutaneous envelope. The ease of its application, its painlessness and its excellent results make it one of the most valuable additions to the dermatologist's list of effective remedies. 